\title{
Predictors of loss to follow-up in antiretroviral treatment for adult patients in the Oromia region, Ethiopia
}

This article was published in the following Dove Press journal:

HIVIAIDS - Research and Palliative Care

26 April 2016

Number of times this article has been viewed

\author{
Abebe Megerso' \\ Sileshi Garoma' \\ Tolosa Eticha ${ }^{2}$ \\ Tilaye Workineh' \\ Shallo Daba ${ }^{3}$ \\ Mihretu Tarekegn ${ }^{3}$ \\ Zelalem Habtamu ${ }^{3}$ \\ 'Department of Public Health, Adama \\ Hospital Medical College, ${ }^{2}$ Department \\ of Pediatrics and Child Health, Adama \\ Hospital Medical College, ${ }^{3}$ Oromia \\ Regional Health Bureau, HIVIAIDS \\ Prevention and Control Division, \\ Addis Ababa, Ethiopia
}

Purpose: It is known that antiretroviral treatment (ART) reduces mortality from acquired immunodeficiency syndrome related causes. Patient's lost to follow-up (LTFU) in this treatment poses a paramount problem to the public and health care services. Information on predictors of loss to follow-up is scarce in this study area and similar settings. Therefore, this study aimed at identifying correlates of loss to follow-up in ART among adult patients in the Oromia region of Ethiopia.

Methods: A case-control study was conducted between February 2015 and April 2015 using medical records. The stratified sampling technique was used to select health facilities. The number of patient records to be included in the study was proportionally allocated to each stratum based on their patient proportion in the regional data. Specific health facilities from which to include the records were randomly selected from a list of the health facilities per stratum. All adult patient records registered as LTFU (416) in the selected health facilities during the 12-month period prior to the data collection date, and 832 patients with good adherence to ART were included. Data were double-entered into Epi Info 7 and analyzed using SPSS 20. Descriptive statistics and binary logistic regression were used to report the results. Qualitative data were thematically analyzed using open code computer software.

Results: Age 15-24 years (adjusted odds ratio [AOR], 19.82 95\% CI: 6.80, 57.73); day laborers (AOR, 5.36; 95\% confidence interval [CI]: 3.23, 8.89), rural residents (AOR, 2.35; 95\% CI: 1.45, 3.89), World Health Organization clinical stage IV (AOR, 2.29; 95\% CI: 1.45, 3.62), baseline CD4 $<350$ cells/mL (AOR, 2.06; 95\% CI: 1.36, 3.13), suboptimal adherence to ART (AOR, 7.42; 95\% CI: 1.87, 29.41), were factors which increased the risk of loss to follow-up in ART. Conclusion: Multiple risk factors, both socioeconomic and clinical, were associated with loss to follow-up. Attention is required to address these factors during patient preparation for the treatment and follow-up counseling by practitioners. We recommend that other studies identify what happened to the patients registered as LTFU as the current study could not address this issue.

Keywords: ART, lost to follow-up, adult, associated factors, case control, Oromia region

\section{Introduction}

The AIDS pandemic is currently the world's most deadly "war" which has killed 25 million people since it was first recognized in 1981, making it one of the most destructive epidemics in recorded history. ${ }^{1}$ In 2010 there were 34 million people living with HIV (PLWHIV) worldwide and the majority of them were from sub-Saharan Africa. ${ }^{2,3}$ The annual number of people dying from AIDS-related causes worldwide is steadily decreasing from a peak of 2.2 million in 2005 to an estimated 1.8 million in $2010 .{ }^{4}$ Moreover, following the introduction of antiretroviral treatment (ART) in 1995, a total
Correspondence: Abebe Megerso Department of Public Health, Adama Hospital Medical College, P.O.Box 3092, Adama, Ethiopia Email: abemegerso@yahoo.com (c) (1) () 2016 Megerso et al. This work is published and licensed by Dove Medical Press Limited. The full terms of this license are available at https://www.dovepress.com/terms. cC. you hereby accept the Terms. Non-commercial uses of the work are permitted without any further permission from Dove Medical Press Limited, provided the work is properly attributed. For permission for commercial use of this work, please see paragraphs 4.2 and 5 of our Terms (https://www.dovepress.com/terms.php). 
of 2.5 million deaths have been averted in low and middle income countries. ${ }^{3}$ This is because of the increased availability of ART to PLWHIV, especially in sub-Saharan Africa; and fewer people have been newly infected with HIV since the late 1990s. ${ }^{4}$ The advent of ART has made HIV a manageable chronic illness; however, most PLWHIV or at risk for HIV do not have access to prevention, care, and treatment, and there is still no cure. ${ }^{5}$

Sub-Saharan Africa remains as the bearer of higher burden of the HIV/AIDS epidemic accounting for 24.7 million or $63 \%$ of all persons infected with HIV. ${ }^{6}$ Initially, efforts to confront the AIDS epidemic were primarily concentrated on access to antiretroviral drugs. ${ }^{6,7}$ However, the increasing availability and affordability of antiretroviral drugs, among other things, has dramatically facilitated the scaling up of ART programs worldwide. ${ }^{6}$ It was in the late 1990 s, that a combination of ART was introduced, and patient adherence to the treatment and retention in care emerged as a vital issue to sustain the efficacy of these potent regimens. ${ }^{8}$ The main goals of HIV infection treatment have been the suppression of viral replication, restoration of the immune response, halting the progression of disease, increased survival rates, reduced morbidity, and a better quality of life. ${ }^{6,7}$ Thus, the use of ART has revitalized communities and transformed perceptions of HIV/AIDS from being a plague to a manageable chronic illness. ${ }^{9}$ Noticing the benefits of ART, countries have been expanding access to ART. ${ }^{10,11}$ The rapid expansion of ART is one of the most remarkable achievements in recent public health history. ${ }^{12}$ The World Health Organization (WHO) has recently recommended initiating ART with higher CD4 cells count, up to 500 cells per micro-liter of blood. ${ }^{6,13}$ More generally, access to ART has been increasing with time, and this expansion has helped the program reach millions of people living with HIV/AIDS (PLWHIV). ${ }^{14}$

Loss to ART follow-up poses a serious challenge in the success of ART programs in resource-poor settings. ${ }^{15}$ Patients lost to follow-up (LTFU) may be dead or alive. Those patients who are alive may have self-transferred themselves to another ART clinic; or may not be on any ART treatment anywhere. $^{15}$

ART was introduced in Ethiopia in 2003, and in 2005 the Ethiopian Government launched free access in different health sectors to improve quality of life of PLWHIV. ${ }^{16}$ Because of the wide availability and use of a free ART service that began to operate in 2005 with the support of the donor organizations, HIV/AIDS related morbidity and mortality has decreased significantly in Ethiopia. ${ }^{17}$ Ethiopia has been scaling up ART toward universal access. ${ }^{10,18}$ At the end of 2013, the number of patients ever started on ART reached 439,301 in Ethiopia, and 317,443 (72.3\%) were receiving the service from 913 health facilities (143 hospitals and 770 health centers). ${ }^{19}$ ART service expansion follows a similar scenario in regions of the country. ${ }^{20}$ Retention in care and adherence to the treatment is very important for the success of the program while the treatment is being scaled up. ${ }^{12,21}$ However, loss to follow-up in ART is an obstacle in the success of ART programs in resource limited countries. ${ }^{22}$ In Ethiopia, for instance, routine data supplied to the HIV/ AIDS prevention and control office indicated that many patients had dropped out of ART. ${ }^{19,23}$ By the end of 2012, $81.3 \%(38,286)$ of the patients were alive and on ART after 12 months of treatment initiation, out of the patients who had been started on ART. ${ }^{19,23}$ This attrition from the treatment is unacceptably high. ${ }^{10,13,21}$ Mortality and loss to follow-up were major reasons for the non-retention. ${ }^{20,23}$ Although there are a few single facility based evidences on factors affecting loss to follow-up in ART, Oromia region wide and multifacility based evidences are required to guide the program toward maximized success addressing context specific factors affecting case retention.

\section{Methods \\ Study setting}

The study was conducted in Oromia region in randomly selected ART service delivery institutions. Oromia national regional state is one of the largest and most populous regions in Ethiopia. ${ }^{21,24}$ This region shares common boundaries with all regions except Tigray. The two city administrations, Addis Ababa and Dire Dawa, are also surrounded by administrative zones of the region. Being the largest region that covers the central land mass of the country, Oromia includes high HIV prevalence "corridors". As a result of these features of the region, a study conducted in this region was believed to show the national picture related to the studied issues. According to the national HIV/AIDS related estimate and projections for Ethiopia, the prevalence of HIV infection in 2014 was $1.2 \%$ ( $1.6 \%$ and $0.8 \%$ of women and men respectively) among the adult population. ${ }^{24}$

The HIV/AIDS situation in Oromia region is not different from that of the national data. The Oromia regional state has 42 hospitals and over 1,300 health centers. ${ }^{24}$ From these health facilities, 318 (42 hospitals and 276 health centers and other non-governmental health institutions), are providing ART services to over 80,780 patients currently. The health facilities are grouped into seven clusters according to the Ethiopian Hospitals Alliance for Quality by the Oromia Regional Health 
Bureau. Under these clusters, there are different numbers of hospitals and health centers delivering ART services.

\section{Study period}

The study was conducted during the period of February 2015 to April 2015. Data collection was executed during the second half of March and the first week of April, while the other weeks of the study period were dedicated for research planning and analysis. Medical records of all patients recorded as LTFU during January 2015 to December 2015 were included in the current analysis.

\section{Study design}

An unmatched case-control study design was employed.

\section{Source population}

The source population for this study was all adult people living with HIV/AIDS who had been started on ART in the Oromia region.

\section{Study population}

The study population was all patients on ART with optimum adherence to the treatment and those who were currently registered as LTFU in the selected health facilities.

\section{Study units}

The study units were individual patients who were registered as LTFU during the 12 months prior to the survey. These were taken as cases. The controls were ART adherent cases (with adherence to ART of $95 \%$ or more) selected from the patients known to be adherent to the treatment.

\section{Sampling technique}

In this study, we used a multi-stage sampling approach. First, Oromia region was stratified into four strata based on the ecological and socio-cultural relative similarity. The first stratum was the west and southwest of the region. The second stratum was the central part of the region. The third stratum was the southern and southeastern part of the region, and the final stratum was the eastern part of the region.

Secondly, based on the latest monthly regional health bureau report, ${ }^{24}$ we identified all health facilities with at least 500 ART patients at the start of the study. We used this patient load as inclusion criteria for the health facilities in the study in order to obtain the required sample from the facility. The latest regional health bureau ART data were also used to identify the proportion of ART patients per the four strata. After identifying health facilities with higher patient loads, the proportions of patients per stratum were determined and this proportion was used to determine the number of health facilities to be included in the study from each stratum. The health facilities were randomly selected from the list of health facilities in the strata.

Then, the health facility database was used to extract the information for all adult patients on ART who had missed follow-up appointments for 90 days or longer from their last appointment date during the 12-month period prior to the data collection. Based on the number of identified LTFU cases, another two adult patients with good adherence to ART were randomly selected from the respective health facilities using SPSS Statistics for Windows, Version 20.0 (IBM Corporation, Armonk, NY, USA). During the 12 months prior to the data collection date, 416 patients were registered as LTFU in the selected health facilities. With the case to control ratio of one to two, 832 patients with good adherence to ART were randomly selected as controls. Therefore, the total sample size of 1,248 was used for the analysis of factors associated with loss to follow-up in ART in the region.

\section{Data collection procedures}

Both quantitative and qualitative approaches were used to collect data. Semi-structured and pre-tested questionnaires were used to collect data for the ART adherent patients. Data extraction tools were also used to extract secondary data from the medical records of these patients. The same data extraction tools were used to collect data on the baseline and treatment history of ART patients, and to collect baseline and follow-up data for the patients LTFU.

Trained data collectors interviewed patients using the questionnaire. Secondary data of respective patients were also collected by other trained data collectors. The patient and their medical records were linked by using the unique ART number that identifies the patient. Data of the LTFU patients were collected by trained supervisors using the predesigned data extraction tool. Qualitative data were collected by trained and experienced qualitative data collectors. Additionally, key informants, who were providing ART service were also interviewed to supplement qualitative data using pre- designed interview guides.

\section{Data management (processing and analysis)}

Completed data collection tools were double checked by the trained supervisors and the principal investigators before data entry. Data were double entered into Epi Info version 7. The data were exported to SPSS for Windows version 20 
for cleaning and analysis. The exported data were cleaned by using computer facilities helpful in cleaning data. We prepared the data for analysis by recoding them as per the requirement for the analysis.

Appropriate statistical analysis models were used based on whether or not the variable of interest fulfilled the assumptions required by the models. Binary logistic regression was used to perform bivariate and multivariate analyses. Before multivariate analysis was performed, univariate analysis was done to check for crude association between the dependent variable (patient follow-up status) and individual independent variable which is expected to be associated with the dependent variable based on existing knowledge. Then, all independent variables with $P$-value smaller than or larger than but closer to the significance level $(0.05)$ were entered into the model to identify independent predictors while controlling for confounders. Multi-collinearity was checked to rule out the interaction among the independent variables, and any independent variable with greater than $60 \%$ of collinearity was dropped from the analysis. Collinearity between categorical variables was assessed by looking at the values of variance inflation factors, and those larger than 10 were excluded from the fitted model. ${ }^{25}$ A confidence level of $95 \%$ was used to determine statistical significance and $P$-value of less than or equal to 0.05 was considered as statistically significant result.

To analyze qualitative information, each in-depth interview was tape-recorded and transcribed verbatim in the regional language (Afan Oromo). Later, it was translated into English by the investigators. To ensure the validity of the translation, another person, proficient in both languages, checked and commented on it so as to incorporate changes into the report. Following the steps of qualitative thematic content analysis, ${ }^{26,27}$ the texts were imported into the Open Code 2007 program to facilitate the coding process. ${ }^{28}$ After reading the transcripts, the researchers performed open coding of the texts, constantly comparing similarities and differences among interviewees by going back to the original text. In the next step, selective coding was performed and relevant codes were further conceptualized leading to the development of categories. Several categories were combined to form themes. During the coding process, relevant quotations from transcripts were put into memos and incorporated to illustrate main ideas during the write-up. Finally, understanding of multiple forms of information collected, and triangulation of different data sources was performed to verify the findings.

\section{Data quality assurance}

As a measure to ensure data quality, we trained the supervisors and data collectors on the data collection tools. They were also involved in the pre-testing of the tools as part of the training. The data collection tools were pre-tested and they were checked for consistency and amended as deemed necessary after the pre-testing. During the data collection, assigned supervisors closely monitored the data collectors both for the validity of the data and ethical issues. Data were also checked for completeness before data entry. A predeveloped Epi Info based data entry template was designed and given to data entry clerks. Double entry of the data and thorough cleaning were the other activities performed to ensure data quality.

\section{Ethical consideration}

The ethical approval was secured from Oromia Regional Health Bureau ethical review committee. An accompanying letter of permission was also obtained from the regional health bureau for all included health facilities. Regarding the study participants, a consent form was prepared, and participants who were on the treatment during the data collection period were informed, to decide whether or not to participate in the study. Written informed consent was obtained from patients or from the parents, caregivers or next of kin for participants who were under 18 years of age. The study participants were informed that they had the right to discontinue or refuse to participate in the study. For the LTFU cases, assent was obtained from respective health facilities before the data extraction. Confidentiality of the information was assured and privacy of the respondents was maintained by avoiding all identifiers and using codes to identify records at analysis.

\section{Results \\ Socio-demographic characteristics}

A total of 416 LTFU cases were registered in the selected health facilities 12 months preceding the date of the survey. By selecting two adherent patients as control for each patient LTFU, 832 patients on the treatment were randomly selected. Accordingly, a total of 1,248 patient records were analyzed. The median age of the cases was 30 years with interquartile range of 25-38 years, and that for the controls was 36.0 (interquartile range, 30-45). This age is significantly different for the two groups $(P<0.001)$; but as both groups are in the adult age range for the treatment, they can be compared to respective risk associations. The majority of the cases and controls were females, comprising $56.7 \%$ and $66.0 \%$, 
respectively. Similarly, the majority of the cases $(76.5 \%)$ and controls $(86.3 \%)$ were urban dwellers. The educational status of the larger proportions of both groups was categorized as elementary or lower level of education. The majority of the cases were day laborers (51.4\%), while that of the controls were employees $(36.3 \%)$ (Table 1$)$.

The baseline clinical characteristics of both groups were analyzed and showed that $\sim 39.7 \%$ of the cases were WHO clinical stage III $^{6,7}$ while $\sim 40.6 \%$ of the controls were stage I at the start of the treatment. Most of the initial functional statuses of cases and controls were working, $84.1 \%$ and $97.2 \%$ respectively. A smaller proportion of both the cases (16.4\%) and controls (17.7) had a history of tuberculosis (TB) treatment. About $46.4 \%$ of the controls were given isoniazid prophylactic therapy (IPT) at least once during the follow-up period while only $23.6 \%$ of the cases were given IPT. The largest proportion of the cases and controls had a CD4 count of less than 350 cells $/ \mathrm{mL}, 77.9 \%$ and $66.8 \%$ respectively, at the start of the ART. The most common last treatment regimen for both cases and controls was tenofovir + lamivudine + efavirenz (TDF+3TC+EFV), 65.7\% and 51.7\% respectively (Table 2).

Bivariate and multivariate analyses were conducted to establish the association between the study variables. From the socio-demographic variables, sex, age, residence, marital status, educational status, and occupation of the respondents were significantly associated with loss to follow-up in ART. Similarly, the association of baseline clinical characteristics like baseline functional status, WHO stage, baseline CD4, treatment stage, last treatment regimen, registered adherence status, and history of IPT were significantly associated with

Table I Socio-demographic characteristics and their association with loss to follow-up in ART, Oromia regional state, Ethiopia, 2015

\begin{tabular}{|c|c|c|c|c|}
\hline \multirow[t]{3}{*}{ Variables } & \multicolumn{2}{|c|}{ Last follow-up status } & \multirow{3}{*}{$\begin{array}{l}\text { Crude odds ratio } \\
(95 \% \mathrm{Cl})\end{array}$} & \multirow{3}{*}{$\begin{array}{l}\text { Adjusted odds } \\
\text { ratio }(95 \% \mathrm{CI})\end{array}$} \\
\hline & Cases (LTFU) & Controls & & \\
\hline & $\mathbf{N}(\%)$ & $\mathbf{N}(\%)$ & & \\
\hline \multicolumn{5}{|l|}{ Sex } \\
\hline Male & $180(43.3)$ & $283(34.0)$ & $1.48(1.16,1.88)^{*}$ & $2.04(1.38,3.02)^{* * *}$ \\
\hline Female & $236(56.7)$ & $549(66.0)$ & Reference category & Reference category \\
\hline \multicolumn{5}{|l|}{ Age category } \\
\hline $15-24$ years & $88(2 \mid .3)$ & $49(5.6)$ & $8.34(4.22,16.48)^{* *}$ & $19.82(6.80,57.73)^{* *}$ \\
\hline $25-34$ years & $157(38.1)$ & $269(32.8)$ & $2.55(I .38,4.7 \mathrm{I})^{*}$ & $3.00(1.18,7.56)$ \\
\hline $35-44$ years & I | 4 (27.7) & $289(35.4)$ & $\mathrm{I} .72(0.93,3.20)$ & $2.50(0.98,6.34)$ \\
\hline $45-54$ years & $39(9.5)$ & I54 (I8.6) & I.I $2(0.57,2.2 \mathrm{I})$ & $0.75(0.27,2.05)$ \\
\hline \multirow[t]{2}{*}{$\geq 55$ years } & $18(3.4)$ & $71(7.5)$ & Reference category & Reference category \\
\hline & \multicolumn{4}{|c|}{ Median age (cases) =30 years (IQR 25-38), median age (controls) =36 (IQR 30-45 years) } \\
\hline \multicolumn{5}{|l|}{ Residence } \\
\hline Urban & $318(76.4)$ & $718(86.3)$ & Reference category & Reference category \\
\hline Rural & $98(23.6)$ & II4 (13.7) & $1.93(1.42,2.62)^{*}$ & $2.37(1.45,3.89)^{* *}$ \\
\hline \multicolumn{5}{|l|}{ Marital status } \\
\hline Single & $103(24.9)$ & $135(16.2)$ & $1.90(1.39,2.59)^{*}$ & \\
\hline Married or cohabiting & 170 (4I.2) & $423(50.8)$ & Reference category & \\
\hline Separated/widowed/divorced & 143 (33.9) & $274(32.9)$ & $1.27(0.97,1.67)$ & \\
\hline \multicolumn{5}{|l|}{ Religion } \\
\hline Muslim & $79(18.9)$ & $105(12.6)$ & $1.70(\mathrm{I} .22,2.36)^{*}$ & Non-significant \\
\hline Orthodox & $256(61.7)$ & $580(69.7)$ & Reference category & \\
\hline Protestant & $76(18.2)$ & 140 (I6.8) & I.22 (0.89, I.68) & \\
\hline Others & $5(1.2)$ & $7(0.8)$ & $1.65(0.52,5.25)$ & \\
\hline \multicolumn{5}{|l|}{ Educational status } \\
\hline Unable to read and write & 135 (32.4) & $200(24.0)$ & $1.46(1.07,1.99)^{*}$ & Non-significant \\
\hline Read and write/Elementary & $163(39.1)$ & $376(45.2)$ & $0.94(0.70,1.25)$ & \\
\hline High school and above & I I 8 (28.5) & $256(30.8)$ & Reference category & \\
\hline \multicolumn{5}{|l|}{ Occupation } \\
\hline Day laborer & $214(5 \mid .4)$ & $211(25.4)$ & $5.20(3.69,7.32)^{* * *}$ & $5.36(3.23,8.89)^{* * *}$ \\
\hline Employee & 140 (33.6) & $302(36.3)$ & $2.37(1.67,3.36)^{* *}$ & $3.21(1.91,5.40)^{* *}$ \\
\hline Others/Farmer, house wife etc & $62(15.0)$ & $319(38.3)$ & Reference category & Reference category \\
\hline
\end{tabular}

Note: Variables in the table were entered into the model to adjust for a possible confounding effect of one variable on the other $*$ represents $P<0.05$, **represents $P<0.01$, ****represents $P<0.001$.

Abbreviations: LTFU, lost to follow-up; ART, antiretroviral treatment; Cl, confidence interval; IQR, interquartile range. 
Table 2 Baseline clinical characteristics and their association with loss to follow-up in ART, Oromia regional state, Ethiopia, 2015

\begin{tabular}{|c|c|c|c|c|}
\hline \multirow[t]{2}{*}{ Variables } & \multicolumn{2}{|c|}{ Last follow-up status } & \multicolumn{2}{|l|}{ Odds ratios } \\
\hline & $\begin{array}{l}\text { Cases (LTFU) } \\
\mathbf{N}(\%)\end{array}$ & $\begin{array}{l}\text { Controls } \\
\mathbf{N}(\%)\end{array}$ & Crude odds ratio $(95 \% \mathrm{Cl})$ & $\begin{array}{l}\text { Adjusted odds } \\
\text { ratio }(95 \% \mathrm{Cl})\end{array}$ \\
\hline \multicolumn{5}{|c|}{ Baseline functional status } \\
\hline Working & $350(84.1)$ & $808(97.2)$ & Reference category & Reference category \\
\hline Ambulatory/bedridden & $66(15.9)$ & $23(2.8)$ & $6.62(4.06,10.82)^{* * *}$ & $2.11(1.04,4.30)^{* *}$ \\
\hline \multicolumn{5}{|l|}{ WHO clinical stage } \\
\hline WHO stage I & II 3 (27.2) & $337(40.6)$ & Reference category & Reference category \\
\hline WHO stage II & $94(22.6)$ & $320(38.6)$ & $0.88(0.64,1.20)$ & $0.75(0.47, \mathrm{I} .18)$ \\
\hline WHO stage III & $165(39.7)$ & $161(19.4)$ & $3.06(2.26,4.14)^{* *}$ & $2.29(1.45,3.62)^{* * *}$ \\
\hline WHO stage IV & $44(10.6)$ & $12(1.4)$ & $10.94(5.58,21.43)^{* * *}$ & $6.25(2.36,16.55)^{* * *}$ \\
\hline \multicolumn{5}{|l|}{ Baseline CD4 } \\
\hline$<350$ cells $/ \mathrm{mL}$ & $285(77.9)$ & $530(66.8)$ & $\mathrm{I} .75(\mathrm{I} .3 \mathrm{I}, 2.34)^{*}$ & $2.06(1.36,3.13)^{* * *}$ \\
\hline$\geq 350$ cells $/ \mathrm{mL}$ & $81(22.1)$ & $255(33.2)$ & Reference category & Reference category \\
\hline \multicolumn{5}{|l|}{ Treatment stage } \\
\hline Treatment stage I & $278(70.6)$ & $790(95.2)$ & Reference category & Reference category \\
\hline Treatment stage II & $59(\mid 5.0)$ & $28(3.4)$ & $6.00(3.74,9.58)^{* *}$ & $8.80(4.68,16.54)^{* * *}$ \\
\hline Treatment stage III & $44(11.2)$ & $10(1.2)$ & $12.50(6.21,25.18)^{* *}$ & $8.89(3.24,24.35)^{* * *}$ \\
\hline Treatment stage IV & $13(3.3)$ & $2(0.2)$ & $18.47(4.14,82.37)^{* *}$ & $11.15(1.74,71.46)^{* * *}$ \\
\hline \multicolumn{5}{|c|}{ Last regimen/used at time of interview } \\
\hline $\mathrm{TDF}+3 \mathrm{TC}+\mathrm{EFV}$ & $272(65.7)$ & $430(51.7)$ & $2.25(1.66,3.05)^{* *}$ & $1.58(1.02,2.44)^{* *}$ \\
\hline $\mathrm{AZT}+3 \mathrm{TC}+\mathrm{NVP}$ & $70(16.9)$ & $249(29.9)$ & Reference category & Reference category \\
\hline Others & $72(17.4)$ & $153(18.4)$ & $1.67(1.14,2.46)^{* *}$ & $1.93(1.10,3.39)^{* *}$ \\
\hline \multicolumn{5}{|c|}{ Adherence status (logbook) } \\
\hline Optimal (Good) & $382(94.1)$ & $824(99.2)$ & Reference category & Reference category \\
\hline Sub-optimal (Fair/Poor) & $24(5.9)$ & $7(0.8)$ & $7.40(3.16,17.31)^{* *}$ & $7.42(1.87,29.4 I)^{* *}$ \\
\hline \multicolumn{5}{|l|}{ History of IPT } \\
\hline Has a history of IPT & $96(23.6)$ & $385(46.4)$ & Reference category & Reference category \\
\hline Has no history of IPT & $311(76.4)$ & $445(53.6)$ & $2.80(2.15,3.66)^{* *}$ & $2.83(1.91,4.21)^{* *}$ \\
\hline
\end{tabular}

loss to follow-up in ART $(P<0.05)$. However, variables like a history of TB treatment and history of co-trimoxazole prophylactic therapy were not significantly associated with loss to follow-up in ART.

The study showed that male patients were more likely (adjusted odds ratio [AOR], 2.04; 95\% confidence interval [CI]: $1.38,3.02$ ) to be LTFU in ART than their counterparts. Younger age increased the odds of loss to follow-up in the treatment. Patients aged 15-24 years were about 19 times (AOR, 19.82; 95\% CI: 6.80, 57.73) more likely to be LTFU in the treatment compared to those patients aged $\geq 55$ years. A similar trend was observed in the second age category (25-35 years). Rural residents were more likely (AOR, 2.37; 95\% CI: $1.45,3.89)$ to be LTFU in ART compared to the urban dwellers. Being a farmer or a housewife was related to decreased odds of loss to follow-up in ART compared to day laborers and employees. Accordingly, day laborers (AOR, 5.36; 95\% CI: 3.23, 8.89) and private or government organization employees (AOR, 3.21; 95\% CI: 1.91, 5.40) were more likely to be LTFU in ART compared to others (farmer, housewife etc). However, religion and marital status of the patients, which were significantly associated at bivariate analysis, did not show a significant association at multivariate analysis (Table 1).

Ambulatory $^{6,7}$ or bedridden patients were more likely (AOR, 2.16; 95\% CI: 1.02, 4.61) to be LTFU in ART when compared to baseline functional status of patients who were working. The odds of patients being LTFU in ART increased with increasing WHO clinical stage. That is, patients with WHO clinical stage III (AOR, 2.29; 95\% CI: 1.45, 3.62) and WHO clinical stage IV (AOR, 6.25; 95\%CI: 2.36, 16.55) were more likely to be LTFU from ART compared to WHO clinical stage I. Similar trends were observed for the treatment stages (patient categorization similar to WHO clinical staging; with the difference that treatment stage is used for patients started on ART). Moreover, patients with baseline CD4 count less than 350 cells/mL were (AOR, 2.06; 95\% CI: 1.36, 3.13) more likely to be LTFU in ART compared 
to the reference category (baseline CD4 of $\geq 350$ cells $/ \mathrm{mL}$ ). Patients who were taking a combination of drugs such as $(\mathrm{TDF}+3 \mathrm{TC}+\mathrm{EFV})$ were about two times (AOR, 1.58; 95\% CI: $1.02,2.44)$ more likely to be LTFU in ART compared to those patients who were taking zidovudine + lamivudine + nevirapine $(\mathrm{AZT}+3 \mathrm{TC}+\mathrm{NVP})$. Patients with a history of fair to poor (less than 95\%) adherence status (AOR, 7.42; 95\% CI: $1.87,29.41$ ) and patients with no history of IPT (AOR, 2.83; 95\% CI: $1.91,4.21$ ) were more likely to be LTFU in ART as compared to their counterparts. However, a history of TB treatment and of co-trimoxazole prophylactic therapy were not associated with loss to follow-up in ART (Table 2).

\section{Summary of qualitative findings}

We qualitatively sought for information on factors related to follow up such as: patient related, (for example understanding of the medication), health provider related, health care system related, and socio-economic factors. Major reasons related to LTFU, repeatedly mentioned by the key informants, include: suboptimal quality of health care due to practitioners' work overload, medical record keeping problems, minimal social support for the patients, and poor economic status of the patients. Health care providers, who are formally assigned to ART clinics, were overloaded with additional responsibilities, which was believed to result in lower quality of service. The other critical factor associated with loss to follow-up, was fear of stigma and social exclusion. Many patients do not want to be seen by others, who know them, in a health facility while they are in the ART section. Many patients were coming from distant areas of their respective health institutions as ART services were available at limited centers. Lack of money for transportation was one of the reasons for loss to follow-up. Patients traditionally believe that it is not good to take any medicine on an empty stomach. Based on this belief, many patients stop ART when they do not have enough food to eat (Table 3).

\section{Discussion}

This study utilized both quantitative and qualitative approaches for assessing the level of loss to follow-up in ART, and explored the opinions of health professionals involved in the provision of these services and the case managers as well. We noticed that there were a considerable number of patients LTFU in ART for whom various associated factors were identified.

This study showed that the odds of loss to follow-up is more than two times higher in males than in females. This difference could be attributed to the fact that males were more likely to use addictive substances (AOR, 3.14; 95\% CI: 2.26, 4.36). ${ }^{29}$ The younger age group (15-24 years) was more likely to be LTFU in ART as compared to patients aged 55 years and above. This result is consistent with the report from the study done in Mizan Aman General Hospital which showed that adolescents had a more than two times higher

Table 3 Summary of the qualitative findings

Conditions related to LTFU Description of the conditions as related to loss to follow-up

Suboptimal quality of health care due Practitioners' work overload contributes to loss to follow-up. One of the key informants stated how practitioners' to practitioners' work overload work overload affects service quality:

In this health facility, I was formally assigned to follow-up patients who were lost to follow-up, counseling and adherence follow-up; yet, I was given many different extra responsibilities which made me busy and not able to do effective work on patient preparation for ART and finding LTFU patients. Other health workers who were assigned to provide ART services also have many additional responsibilities and had difficulties to properly manage their patients [...]

Minimal social support and stigma One of the main critical issues related to social factors associated with loss to follow-up, is fear of stigma and related to patients on $A R T$ social exclusion. Many patients do not want to be seen by others in a health facility in the ART department. An informant clarified in terms of specific cases:

Especially government employees are fearful to disclose their health status, rich people, and high status people too. The stigma is very strong. Due to this many people do not want to be seen by others in this clinic. A woman says that it is better to leave the medicine than to be socially excluded [...]

Poor economic status of the Lack of money for transportation was one of the reasons for loss to follow-up. Patients traditionally believe that patients

it is not good to take any medicine on an empty stomach. Based on this belief, many patients stop taking ART when there is not enough food to eat. One of the informants confirmed this:

Economic problem is the main reason we are given from most of the patients when we ask why they missed their ART clinic visit appointment. They say that taking this medicine on an empty stomach is dangerous. Although we teach them regarding this issue, explaining that the medicine should be taken before a meal and that it has no side effects, most of the patients insist that taking the drug on an empty stomach is harmful. Most patients believe that additional, nutritious foods are required for someone taking these drugs [...] 
risk of being LTFU in the treatment. ${ }^{30}$ A study from India also indicated that patients who were below 25 years old or single were more likely to be LTFU. ${ }^{31}$ This might be due to fear of stigma and discrimination, as this younger age group is dependent on others, and independent members of this age group could be more mobile as compared to the older population. This idea is also congruent with the qualitative findings indicating that the younger age groups, especially university students who fear stigmatization, are more prone to being LTFU from ART.

Rural residents were found to be more likely to be LTFU in the treatment. This contrast to urban residents could be due to various factors such as accessibility (distance from treatment centers, transport related costs), level of patient's awareness of the treatment, and social stigma. Day laborers and employees (governmental and non-governmental organizations) were more likely to be LTFU in the treatment. The loss to followup among day laborers might be due to instability in their residence. The employees might have switched to another treatment facility due to fear of stigma.

In the in-depth interview, it was mentioned that unemployment and lack of permanent residence was another feature which contributes toward loss to follow-up in ART. There were patients who had moved away to other cities, neighboring regions, and even to other countries in search of job opportunities. Some patients are mobile and some are prostitutes, changing the hotels they work in from time to time; even moving across towns, and they lack a permanent address. Thus, this may contribute to loss to follow-up in the treatment.

Functional status at the initiation of the current study was a strong predictor of loss to follow-up, indicating that patients who were ambulatory or bedridden were more likely to be LTFU in ART when compared to patients who were working. Consistent with the current finding, are the results from Gonder University Hospital, which showed that ambulatory and bedridden functional status (AOR, 1.65; 95\% CI: 1.22, 2.23) was significantly associated with loss to follow-up..$^{30}$ This might be due to the fact that this group of patients is financially dependent and need close supervision to ensure adherence to ART. They are also more likely to die due to ART side effects within the first 3 months of ART initiation. ${ }^{32,33}$

This study also showed that patients in treatment stage III and IV were more likely to be LTFU. A similar explanation to that of advanced clinical stage can explain the reason for loss to follow-up for this group of patients. This is because another study indicated that half of loss to follow-up in ART was due to death. ${ }^{34}$
Also, patients with baseline CD4 of less than 350 cells/ $\mathrm{mL}$ were more likely to be LTFU in ART. This finding is similar to other studies. ${ }^{35,36}$ This higher likelihood of LTFU among patients with lower CD4 count may be due to advance in disease that could have resulted in death. From the current study, having a history of IPT decreases the risk of loss to follow-up in ART. This result is congruent with that of other studies conducted elsewhere in Ethiopia. ${ }^{30,37}$ Obviously, this can be justified by the fact that TB is the main opportunistic infection resulting in high mortality and loss to follow-up, and hence IPT protects against TB reactivation.

Contrary to the expectation, patients who were on $\mathrm{TDF}+3 \mathrm{TC}+\mathrm{EFV}$ (which is one pill per day) were about two times more likely to be LTFU in ART compared to those patients on AZT+3TC+NVP (which has to be taken twice a day). This could be due to possible side effects associated with this combination. ${ }^{38}$

In the current study, we have identified important predictors of loss to follow-up based on the data we could collect and analyze. We recommend that ART service providers and program implementers should make use of this evidence to focus their attention toward the identified predictors. The limitation of this study was that data were not obtained from the LTFU patients themselves, as tracing the LTFU patients was not easy. Therefore, future studies should attempt to reach the LTFU patients to make the evidence more complete.

\section{Acknowledgments}

We are grateful to Adama Hospital Medical College for funding this work. Oromia Regional Health Bureau deserves special thanks for the ethical approval and letters of permission. We are grateful to other line departments and individuals who played important roles in availing necessary information without which this work would not have been completed. We also appreciate the respective contributions of all supervisors, data collectors, and study participants.

\section{Disclosure}

The authors report no conflicts of interest in this work.

\section{References}

1. Ekouevi DK, Balestre E, Ba-Gomis FO, et al. Low retention of HIVinfected patients on antiretroviral therapy in 11 clinical centers in West Africa. Trop Med Int Health. 2010;15 Suppl 1:34-42.

2. Evangeli M, Newell ML, Richter L, McGrath N. The association between self-reported stigma and loss-to-follow up in treatment eligible HIV positive adults in rural Kwazulu-Natal, South Africa. PLoS One. 2014;9(2):e88235.

3. Micek MA, Gimbel-Sherr K, Baptista AJ, et al. Loss to follow-up of adults in public HIV care systems in Mozambique: identifying obstacles to treatment. J Acquir Immune Defic Syndr. 2009;52(3):397-405. 
4. Thida A, Tun ST, Zaw SK, et al. Retention and risk factors for attrition in a large public health ART program in Myanmar: a retrospective cohort analysis. PLoS One. 2014;9(9):e108615.

5. Geng EH, Nash D, Kambugu A, et al. Retention in care among HIVinfected patients in resource-limited settings: emerging insights and new directions. Curr HIV/AIDS Rep. 2010;7(4):234-244.

6. World Health Organization. Antiretroviral therapy for HIV infection in adults and adolescents: recommendations for a public health approach. World Health Organization; 2006. Available from: http://www.who. int/hiv/pub/guidelines/artadultguidelines.pdf. Accessed January 18, 2016.

7. World Health Organization. The use of antiretroviral therapy: a simplified approach for resource constrained countries. World Health Organization; 2002. Available from: http://apps.searo.who.int/ PDS_DOCS/B0184.pdf. Accessed January 18, 2016.

8. Simoni JM, Amico KR, Smith L, Nelson K. Antiretroviral adherence interventions: translating research findings to the real world clinic. Curr HIV/AIDS Rep. 2010;7(1):44-51.

9. Alagaw A, Godana W, Taha M, Dejene T. Factors associated with antiretroviral treatment adherence among adult patients in Wolaita Soddo Hospital, Wolaita Zone, Southern Ethiopia. Science Journal of Public Health 2014;2(2):69-77.

10. Federal HIV/AIDS Prevention and Control Office Federal Ministry of Health. Guidelines for Implementation of Antiretroviral therapy programme in Ethiopia. Federal HIV/AIDS Prevention and Control Office Federal Ministry of Health; 2007. Available from: http:/www.ilo.org/ wcmsp5/groups/public/_ed_protect/—protrav/—ilo_aids/documents/ legaldocument/wcms_125385.pdf. Accessed January 18, 2016.

11. Rutherford GW, Anglemyer A, Easterbrook PJ, et al. Predicting treatment failure in adults and children on antiretroviral therapy: a systematic review of the performance characteristics of the 2010 WHO immunologic and clinical criteria for virologic failure. AIDS. 2014;28(Suppl 2): S161-S169.

12. Markos E, Worku A, Davey G. Adherence to ART in PLWHA at Yirgalem Hospital, South Ethiopia. Ethiopian Journal of Health Development. 2008;22(2):174-179.

13. World Health Organization [homepage on the Internet]. Consolidated Guidelines on the use of antiretroviral drugs for treating and preventing of HIV infection: Recommendations for a public health approaches World Health Organization; 2013. Available from: http://www.who. int/hiv/pub/guidelines/arv2013/arvs2013upplement_march2014/en/. Accessed January 18, 2016.

14. Reda AA, Biadgilign S. Determinants of adherence to antiretroviral therapy among HIV-infected patients in Africa. AIDS Res Treat. 2012;2012:574656.

15. Geng EH, Bangsberg DR, Musinguzi N, et al. Understanding reasons for and outcomes of patients lost to follow-up in antiretroviral therapy programs in Africa through a sampling-based approach. J Acquir Immune Defic Syndr. 2010;53(3):405-411.

16. Asefa T, Taha M, Dejene T, Dube L. Determinants of defaulting from antiretroviral therapy treatment in Nekemte Hospital, Eastern Wollega Zone, Western Ethiopia Public Health Research. 2013;3(5):130-135.

17. Meloni ST, Chang C, Chaplin B, et al. Time-Dependent Predictors of Loss to Follow-Up in a Large HIV Treatment Cohort in Nigeria. 2014;1(2):ofu055.

18. Ministry of Health Addis Ababa, Ethiopia. Guidelines for the implementation of antiretroviral therapy in Ethiopia. Ministry of Health Addis Ababa, Ethiopia; 2005. Available from: http://www.etharc.org/oromia/ resources/publication/ethartguide.pdf. Accessed January 18, 2016.

19. Federal Democratic Republic of Ethiopia, HIV/AIDS Prevention and Control Office (HAPCO). Country progress report on the HIV response, 2014. Federal Democratic Republic of Ethiopia; 2014. Available from: http://www.unaids.org/sites/default/files/country/documents/ ETH_narrative_report_2014.pdf. Accessed January 18, 2016.
20. Oromia Regional Health Bureau. Annual programme performance Report. Addiss Ababa: Oromia Regional Health Bureau; July, 2014 2013/14. Available from: www.unaids.org/sites/default/files/.../ETH_ narrative_report_2014.pdf. Accessed January 20, 2016.

21. World Health Organization [homepage on the Internet]. Global update on HIV treatment 2013: results, impact and opportunities. World Health Organization; 2013. Available from: http://www.who.int/hiv/ pub/progressreports/update2013/en/. Accessed January 18, 2016.

22. Rosen S, Fox P, Gill CJ. Patient retention in antiretroviral therapy programs in sub-Saharan Africa: a systematic review. Plos Med. 2007;4(10):e298.

23. Ethiopian monthly antiretroviral treatment report. June 2008. Addis Ababa2008.

24. ORHB. Oromia Regional Health Bureau Report 2013/14.

25. Glantz SA, Slinker BK. Primer of applied regression and analysis of variance. New York: McGraw-Hill Education; 2001.

26. Oromia Regional state Health Bureau. Annual performance report on HIV/AIDS prevention and control. Oromia Regional state Health Bureau; 2014. Available from: www.moh.gov.et/oromiahb2014. Accessed January 18, 2016.

27. Federal Democratic Republic of Ethiopia Ministry of Health. Health Sector Development Program IV, 2010/11 - 2014/15. Federal Democratic Republic of Ethiopia Ministry of Health; 2013. Available from: http://www.ccghr.ca/wp-content/uploads/2013/11/ healthsectordevelopmentprogram.pdf. Accessed January 18, 2016.

28. Alemu AW, Sebastián MS. Determinants of survival in adult HIV patients on antiretroviral therapy in Oromiyaa, Ethiopia. Glob Health Action. 2010;3:5398.

29. Geng EH, Bangsberg DR, Musinguzi N, et al. Understanding reasons for and outcomes of patients lost to follow-up in antiretroviral therapy programs in Africa through a sampling-based approach. J Acquir Immune Defic Syndr. 2010;53(3):405-411.

30. Wubshet M, Berhane Y, Worku A, Kebede Y, Diro E. High loss to followup and early mortality create substantial reduction in patient retention at antiretroviral treatment program in north-west Ethiopia. ISRN AIDS. 2012;2012:721720.

31. Alvarez-Uria G, Naik PK, Pakam R, Midde M. Factors associated with attrition, mortality, and loss to follow up after antiretroviral therapy initiation: data from an HIV cohort study in India. Glob Health Action. 2013;6:21682.

32. Biadgilign S, Deribew A, Amberbir A, Deribe K. Adherence to highly active antiretroviral therapy and its correlates among HIV infected pediatric patients in Ethiopia. BMC Pediatr. 2008;8:53.

33. Assefa T, Wencheko E. Survival analysis of patients under chronic HIVcare and antiretroviral treatment at Tikur Anbessa Specialized Hospital, Addis Ababa, Ethiopia. Ethiopian Journal of Health Development. 2012;26(1):22-29.

34. Bhatta L, Klouman E, Deuba K, et al. Survival on antiretroviral treatment among adult HIV-infected patients in Nepal: a retrospective cohort study in far-western region, 2006-2011. BMC Infect Dis. 2013;13:604.

35. Morris JD, Golub ET, Mehta SH, Jacobson LP, Gange SJ. Injection drug use and patterns of highly active antiretroviral therapy use: an analysis of ALIVE, WIHS, and MACS cohorts. AIDS Res Ther. 2007;4:12.

36. Yu JK, Chen SC, Wang KY, et al. True outcomes for patients on antiretroviral therapy who are "lost to follow-up" in Malawi. Bull World Health Organ. 2007;85(7):550-554.

37. Dessalegn M, Tsadik M, Lemma H. Predictors of lost to follow up to antiretroviral therapy in primary public hospital of Wukro, Tigray, Ethiopia: A case control study. Journal of AIDS and HIV Research. 2015;7(1):1-9.

38. Diop SA, Fortes-Déguénonvo L, Seydi M, et al. Efficacy and tolerance of tenofovir-lamivudine-efavirenz combination in HIV-1 patients in Fann Teaching Hospital in Dakar. Bull Soc Pathol Exot. 2013;106(1):22-26. 


\section{Publish your work in this journal}

HIV/AIDS - Research and Palliative Care is an international, peerreviewed open-access journal focusing on advances in research in HIV, its clinical progression and management options including antiviral treatment, palliative care and public healthcare policies to control viral spread. The journal welcomes original research, basic science,

clinical \& epidemiological studies, reviews \& evaluations, expert opinion \& commentary, case reports \& extended reports. The manuscript management system is completely online and includes a very quick and fair peer-review system. Visit http://www.dovepress.com/ testimonials.php to read real quotes from published authors.

Submit your manuscript here: http://www.dovepress.com/hivaids---research-and-palliative-care-journal 